\title{
La sostenibilidad del Sistema para la Autonomía y Atención a la Dependencia durante el trienio 2012-2014: el equilibrio entre costes y financiación
}

\author{
Rafael Beitia \\ Adjunto al director general del Instituto de Mayores y Servicios Sociales (Imserso). \\ Ministerio de Sanidad, Servicios Sociales e Igualdad \\ <rbeitia@imserso.es>
}

\begin{abstract}
Norberaren Autonomia Sustatzeko eta Mendetasunaren Arretarako abenduaren 14ko 39/2006 Legea onartu zenetik, eztabaidarako gai bihurtu dira mendetasunaren arretarako finantzaziorako kostuen inguruko ekarpenak. Artikulu honen xedea da mendeko diren pertsonen arretak 2012. urtetik 2014. urtearen bitartean Mendetasun Sisteman izan duen kostua azaltzea, kostu hori Administrazio publiko desberdinek nola finantzatu duten ezagutzea, eta baita ere kalkulu hori egiteko zein metodologia jarraitu den jakitea. Izan ere, kalkulu hori egiteko oinarri izaten dira autonomia-erkidego bakoitzak urtero onartzen dituzten zerbitzu eta prestazio ekonomikoak, eta bataz besteko kostua ezartzen zaie zerbitzu desberdinei eta bataz besteko zenbateko bat prestazio ekonomikoei. Modu honetara, Mendetasun Sistemaren urteko kostua lortzen da bi faktore horiek erlazionatuz. Lehenik, artikuluan aztertzen dira Administrazio publiko desberdinek Mendetasunaren Sisteman izandako kostu orokorrak 2012. urtetik 2014. urtera bitartean; horren ondoren kostu horien finantziaziorako iturriak zehaztu eta berauen eboluzioa aztertzen da; eta azkenik, aipamen labur bat egiten da finantziazioaren ereduan egin daitezkeen aldaketen inguruan.
\end{abstract}

\section{GAKO-HITZAK:}

Mendetasun Legea, onuradunak, gastu publikoa, zerbitzuak, prestazio ekonomikoak, finantzazioa.
Desde la aprobación de la Ley 39/2006, de 14 de diciembre, de Promoción de la Autonomía Personal y Atención a las Personas en situación de dependencia, las aportaciones para la financiación del coste de atención a la dependencia han sido objeto de debate y controversia. El objetivo de este artículo es mostrar el coste de atención a las personas dependientes por parte del Sistema de Dependencia durante los años 2012 a 2014, y la forma de financiación de ese coste por las distintas Administraciones públicas, así como la metodología seguida para efectuar ese cálculo, que parte de los servicios y prestaciones económicas reconocidos por las comunidades autónomas cada año, y asigna un coste medio a los diferentes servicios y una cuantía media a las distintas prestaciones económica. El coste anual del Sistema de Dependencia se obtendría, así, relacionando ambos factores. De este modo, el artículo comienza estudiando los costes globales generados por el Sistema de Dependencia a las distintas Administraciones públicas, durante los años 2012 a 2014; continúa con la identificación y evolución de las diferentes vías de financiación de este coste; para finalizar con una breve referencia a posibles modificaciones del modelo de financiación.

\section{Palabras Clave:}

Ley de Dependencia, personas beneficiarias, gasto público, servicios, prestaciones económicas, financiación. 


\section{Introducción}

La aprobación de la Ley 39/2006, de 14 de diciembre, de Promoción de la Autonomía Personal y Atención a las Personas en situación de Dependencia -en adelante, Ley de Dependencia-, supuso un importante hito en la construcción del Estado de Bienestar en España. Sin embargo, desde su entrada en vigor, coincidente con el comienzo de la crisis económica, tanto el coste del Sistema de Dependencia como las aportaciones públicas para su financiación han resultado ser objeto de un intenso debate, centrado en su cuantificación, en su suficiencia o insuficiencia (Morán, 2010) y en la procedencia o no de una aportación del beneficiario.

Para centrar este estudio sobre el coste y financiación de la Ley de Dependencia, nos vamos a detener en los tres últimos ejercicios completos, 2012 a 2014, puesto que este periodo, coincidente con alguno de los peores años de la crisis económica afrontada por España durante el último lustro, muestra precisamente unos datos homogéneos, lo que nos facilitará la realización de comparaciones fiables. Para conocer la situación del Sistema para la Autonomía y Atención a la Dependencia, en adelante SAAD, durante esos años, basta con comprobar los datos oficiales del Sistema comunicados por las comunidades autónomas, aprobados definitivamente por el órgano legalmente competente, el Consejo Territorial de Servicios Sociales y del Sistema para la Autonomía y Atención a la Dependencia, y publicados por el Instituto de Mayores y Servicios Sociales, Imserso.

De entre el conjunto de datos publicados, nos centraremos en los de resultados, ya que el resto los podemos considerar de proceso, como el número de solicitudes, que solo aporta información sobre las personas que entienden que podrían hallarse en situación de dependencia y solicitan una valoración, o el dato de dictámenes de valoración, que constituye también un dato de proceso pues tan solo informa sobre el nivel tramitación por cada comunidad autónoma. Los datos de resultado que analizaremos son el número de beneficiarios atendidos con prestación y la tasa de cobertura.

En primer lugar, el número de beneficiarios con prestación, es decir, las personas realmente atendidas: se puede apreciar en el Gráfico 1 que, durante los años 2012 a 2014, las cifras de beneficiarios con prestación se han mantenido en torno a las 750.000 personas. En concreto, el año 2012 finalizó con 751.551 beneficiarios con prestación, en 2013 hubo 753.842 y 2014 se cerró con 745.720 personas beneficiarias atendidas, lo que evidenciaría cuán lejos se encuentra el Sistema de Dependencia, no ya de una pretendida "caída libre" (Montserrat, 2013), sino, ni siquiera, de una supuesta "demolición controlada" (Asociación Estatal de Directoras y Gerentes de Servicios Sociales, 2012), calificativos muy extendidos, quizá por mediáticos, pero alejados de la realidad.

En segundo lugar, la tasa de cobertura que, como muestra el Gráfico 2, refleja el porcentaje que representan estos dependientes atendidos con prestación sobre el total de beneficiarios con derecho.

En definitiva, la verdadera situación del número de personas dependientes atendidas por el Sistema, durante los años 2012 a 2014, atendiendo a valores absolutos, se podría definir como de estabilidad y, atendiendo a valores relativos, de tasa de cobertura, de crecimiento sostenido.

Gráfico 1. Personas beneficiarias de prestación del Sistema para la Autonomía y Atención a la Dependencia. 2008-2014

900.000
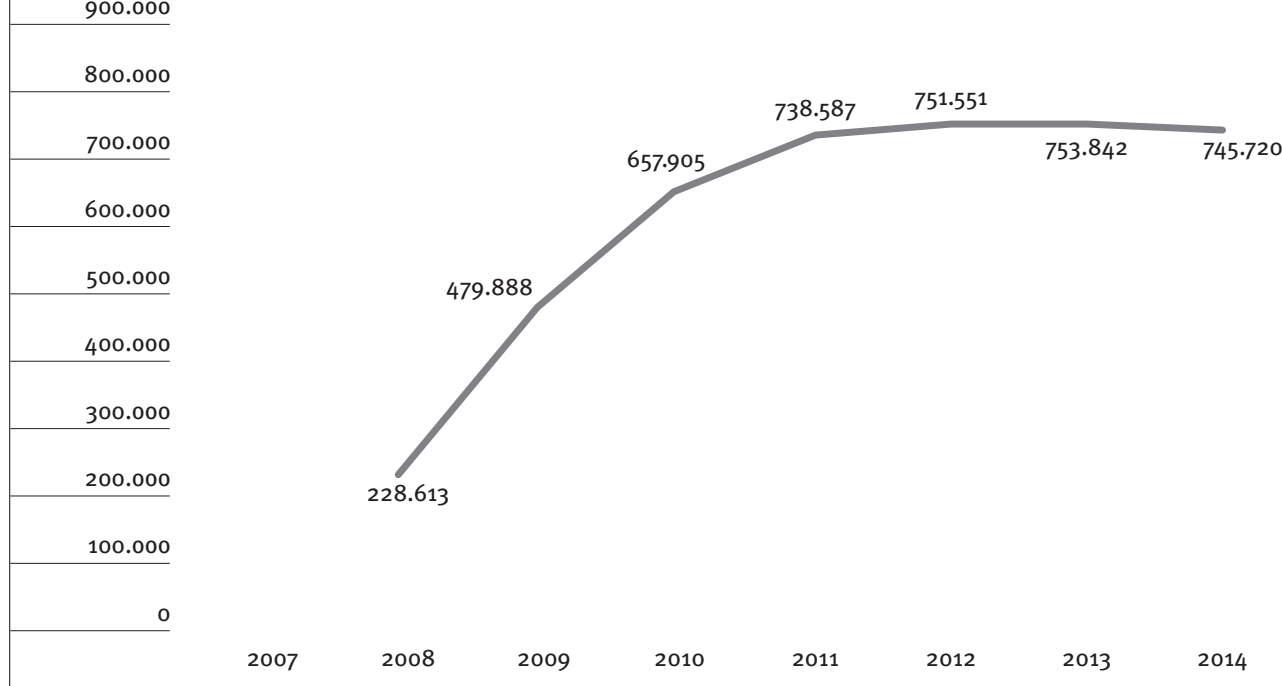

Fuente: Sistema de Información del Sistema para la Autonomía y Atención a la Dependencia (SISAAD). Datos regularizados de acuerdo con los Informes $977 / 2013$ y 1.035/2014 del Tribunal de Cuentas. Elaboración propia. 


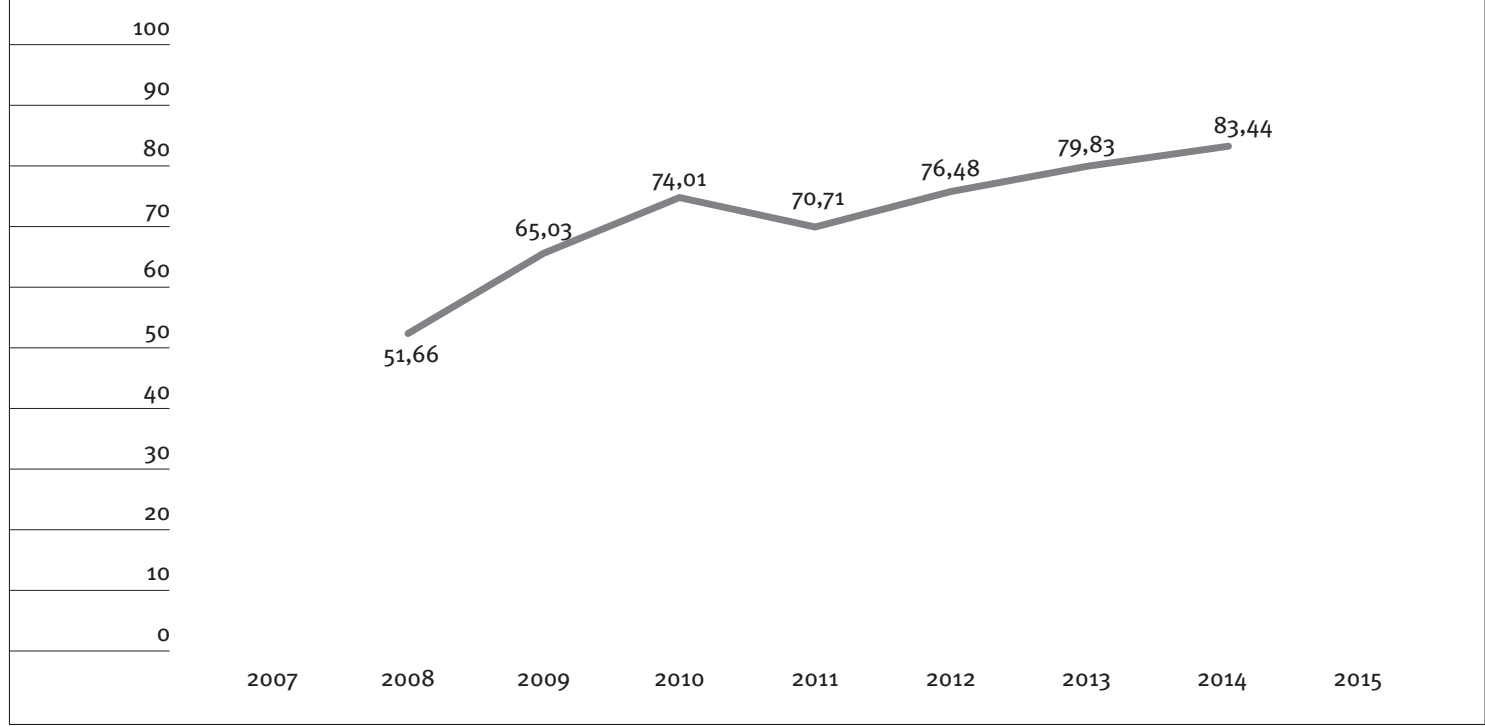

Fuente: Sistema de Información del Sistema para la Autonomía y Atención a la Dependencia (SISAAD). Elaboración propia.

El objeto de este artículo es fijar el coste de esas $751.551,753.842$ y 745.720 personas atendidas por el Sistema de Dependencia en los años 2012, 2013 y 2014, respectivamente, y exponer cómo se ha financiado.

\section{Determinación de los costes del Sistema de Dependencia: metodología y resultado}

Existe una relación directa entre la financiación y los costes de la atención a la dependencia, por lo que para conocer aquélla se hace necesario en primer lugar estimar éstos ${ }^{1}$.

\subsection{Antecedentes}

La Memoria de Análisis de Impacto Normativo del Anteproyecto de Ley de Dependencia recogía la preexistencia de situaciones de dependencia ya atendidas por los servicios sociales públicos² ${ }^{2}$. Este documento determinó que el coste de la atención a esas situaciones de dependencia en 2006 para las Administraciones Públicas rozaba ya los 1.777 millones de $€$, como se puede apreciar en la Figura 1 , reproducción de la página 45 de la Memoria. Además, estimó que el coste total del Sistema de Dependencia en 2015, con un índice de implantación de la Ley al $100 \%$, sería de 9.355 millones de $€$.

${ }^{1}$ El Tribunal de Cuentas (2014) señala en su Informe sobre las medidas de gestión y control adoptadas por las comunidades autónomas para la adecuada aplicación de la Ley de Dependencia, que no resulta nada sencillo poder estimar el coste que supone la atención a la Dependencia en cada año dada la falta de datos relativos a las aportaciones realizadas, tanto por las comunidades autónomas como por las propias personas beneficiarias.

${ }^{2}$ Ministerio de Trabajo y Seguridad Social (2006).
También se advierte en la Figura 1 que la Memoria de Análisis de Impacto de la Ley de Dependencia distinguió una triple fuente de financiación: la Administración General del Estado, las comunidades autónomas y los propios beneficiarios del Sistema de Dependencia.

La Memoria estimó que, en 2015, el coste para las Administraciones Públicas sería el resultante de la suma del entonces "coste actual de los servicios para las Administraciones Públicas”, los casi 1.777 millones de euros citados anteriormente, más lo que definió como el "coste total nuevo para las Administraciones Públicas”, casi 4.426 millones de euros. La suma de ambos conceptos alcanzaría un total de coste para las Administraciones Públicas de casi 6.203 millones de euros, que debía ser asumido a partes iguales, según recogía la propia Memoria, por Administración General del Estado y comunidades autónomas, es decir, unos 3.101,5 millones de euros cada uno en 2015.

Del mismo modo, la Memoria consideró que, de aquellos 9.355 millones de euros de coste total de la dependencia estimados para 2015, un tercio correspondería a la aportación de los mismos beneficiarios, en concreto, casi 3.153 millones de $€$, un $33,7 \%$ del total, tal y como se puede comprobar en la Figura 1.

Por lo tanto, uno de los extremos que se tratan de discernir en este artículo es si el coste del Sistema de la Dependencia en cada uno de los años del periodo 2012-2014 resulta congruente con estas previsiones de la Memoria de Análisis de Impacto de la Ley. 


\section{a) Costes de la dependencia}

El modelo de atención a la autonomía personal y a la dependencia, que a continuación se valora económicamente, es aquel en el que los poderes públicos ofrecen un servicio de atención a las personas con dependencia cuando cuentan con la infraestructura de centros y servicios para ello, procediendo, en caso contrario, al pago de una prestación económica vinculada a la adquisición en el sector privado de uno de los servicios previstos en el catálogo. Asimismo, se contempla que la persona dependiente pueda ser atendida con cuidados familiares mediante una compensación económica.

\section{Resumen de costes del Sistema}

Total costes directos de servicios y prestaciones nuevos beneficiarios

Prestaciones económicas Seguridad Social y LISMI

(incorporado al coste total)

$4 \cdot 636.607 .538$

395.185 .000

Coste neto de los servicios y prestaciones nuevos beneficiarios

4.241.422.538

$84 \cdot 386.257$

100.000 .000

4.425.808.795

3.152.747.758

1.776.936.000

9.355 .492 .553

100

Coste total del Sistema

Índice de implantación 2015

Coste total nuevo del Sistema para las

Coste para el beneficiario

Coste actual de los servicios para las

Administraciones Públicas

\section{ats}

$-45-$

Fuente: Memoria de Análisis de Impacto Normativo, Económico, de Género e Igualdad de Oportunidades, no Discriminación y Accesibilidad Universal, del Anteproyecto de Ley de Promoción de la Autonomía Personal y de Atención a las Personas en situación de Dependencia.

\subsection{Metodología de cálculo del coste de la atención a la dependencia}

Para determinar el coste de la atención a la dependencia en los años 2012 a 2014, se ha partido de las prestaciones ${ }^{3}$ reconocidas por las comunidades autónomas en cada uno de estos años, proporcionadas por estas y publicadas por

${ }^{3}$ Con el término genérico "prestaciones" nos estamos refiriendo aquí tanto a los servicios del catálogo de la Ley de Dependencia como a las prestaciones económicas. el Imserso. Se han contemplado los servicios ${ }^{4}$ prestados cada año, clasificándolos en distintos escenarios, según la categoría del correspondiente servicio, el grado y nivel de dependencia, el nivel de renta y la comunidad autónoma de residencia.

${ }_{4}$ El artículo 15 de la Ley de Dependencia recoge las tipologías de servicios que se han tenido en cuenta para la realización de este estudio: servicio de teleasistencia., servicio de ayuda a domicilio., servicios de centro de día y noche, y servicios de atención residencial. El servicio de Prevención de las Situaciones de Dependencia y Promoción de la Autonomía Personal (PAPD) se ha excluido de este estudio. 


\section{A. NÚMERO DE PRESTACIONES}

Se han segmentado 934.316 prestaciones de 2012, 916.767 prestaciones del ejercicio 2013 y 898.332 prestaciones del ejercicio 2014 en $\mathbf{4 0 . 2 5 6}$ escenarios de actuación, atendiendo a las siguientes variables:

- Tipo de servicio/prestación ( 5 servicios y 3 prestaciones).

- Grado y nivel de dependencia

(5 grados con nivel y 3 grados sin nivel).

- CC.AA. de residencia (17)

- Periodo (37 meses).

Para un mayor ajuste a la realidad, se han utilizado medias móviles mensuales utilizando 37 meses. $\underset{\text { mes "n" }}{\text { Prestaciones }}=\frac{\text { act. a 31/n }+ \text { act. 31/n-1 }}{2}$
B. CLASIFICACIÓN DE LAS PRESTACIONES

El método de estimación utiliza una matriz de prestaciones que comprende 33.728 escenarios, distinguiendo entre:

- Tipo de servicio/prestación (8).

- Grado y nivel de

dependencia (8).

- CC.AA. de residencia (17).

- Tramos de renta (31 tramos).

En el proceso de clasificación de las prestaciones: las 40.256 prestaciones obtenidas en el primer paso (con su clasificación) se anualizan, y se dividen entre los 31 tramos de renta, con lo que se obtienen 33.728 escenarios.

$\frac{40.256 \text { act. }}{37 \text { meses }} \times \begin{gathered}31 \text { tramos } \\ \text { de renta }\end{gathered}=\begin{gathered}\mathbf{3 3 . 7 2 8} \\ \text { escenarios }\end{gathered}$

\section{COSTE DE LAS PRESTACIONES}

La estimación del coste de las prestaciones distingue entre

servicios y prestaciones:

Indicadores del coste de los servicios:

- Se han considerado 3 fuentes de información.

- Los costes de cada fuente se han homogeneizado teniendo en cuenta:

-Plazas públicas/concertadas -Gestión directa/indirecta

-Plazas de mayores/ discapacitados

- Se ha elaborado una matriz de 3 fuentes de información para los 4 servicios y se ha calculado la media para cada uno de los 4 servicios, validando los resultados obtenidos.

Coste de las prestaciones: según el Real Decreto Ley 20/2012 de 13 de Julio, y el acuerdo del Consejo Territorial de 10 de Julio de 2012 se ha distinguido 744 escenarios, según:

- Nivel de renta (31 tramos)

- Grado y nivel de dependencia (8 grados)

- Categoría de prestación

(3 prestaciones)
En cuanto a las prestaciones económicas ${ }^{5}$, se diseñaron diferentes escenarios en función del tipo de prestación, del grado y nivel de dependencia y del nivel de renta de la persona.

Se ha desarrollado un modelo de estimación que distingue, por un lado, servicios y, por otro, prestaciones económicas, asignando a ambos un indicador de referencia: un coste medio a los diferentes servicios y una cuantía media a las diferentes prestaciones económicas. Relacionando ambos factores, es decir, multiplicando el número de prestaciones por el indicador de referencia, según corresponda, se obtiene la cifra del coste anual de atención del Sistema de Dependencia. En la Figura 2 se muestra, resumidamente, esta metodología de estimación.

\subsubsection{Indicadores de coste: cálculo del coste medio de los servicios}

El proceso de cálculo para la obtención del coste medio de los servicios ha considerado tres fuentes de información:

1. El informe Los servicios sociales destinados a las personas mayores en España a 31 de diciembre de 2012, publicado por el Imserso (2015) y que muestra los precios públicos para cada uno de los cuatro servicios.

2. Fuentes del sector de servicios sociales. Datos solicitados por el Imserso a empresas del sector.

3. El estudio Una aproximación al coste de la dependencia en España y su financiación de los profesores de la Universidad de Valladolid Dolores Prada y Luis Borge (2014).

Se han homogeneizado los datos procedentes de las tres fuentes de información, de tal manera que respondan a un esquema de un indicador por servicio expresado en euros al mes o a la hora, según corresponda, como se muestra en la Tabla 1. La media de estos datos es el indicador de coste que se ha utilizado para la estimación del coste medio de los servicios. 
Tabla 1. Indicadores de coste: coste medio de los servicios

\begin{tabular}{|l|c|c|c|c|}
\hline Fuentes & $\begin{array}{c}\text { Teleasistencia } \\
(\boldsymbol{€} / \mathrm{mes})\end{array}$ & $\begin{array}{c}\text { Ayuda a domicilio } \\
(\boldsymbol{€} / \text { hora })\end{array}$ & $\begin{array}{c}\text { Centros de día/noche } \\
(\boldsymbol{€} / \mathrm{mes})\end{array}$ & $\begin{array}{c}\text { Atención residencial } \\
(\boldsymbol{€} / \mathrm{mes})\end{array}$ \\
\hline Imserso (2012) & 23,94 & 14,01 & 861,48 & $1.658,13$ \\
\hline Fuentes del sector & 20,00 & 17,00 & $1.063,52$ & $2.542,54$ \\
\hline Prada y Borge (2014) & 20,00 & 15,00 & 873,06 & $1.774,05$ \\
\hline Indicador de coste & $\mathbf{2 1 , 3 1}$ & $\mathbf{1 5 , 3 4}$ & $\mathbf{9 3 2 , 6 9}$ & $\mathbf{1 . 9 9 1 , 5 7}$ \\
\hline
\end{tabular}

Fuente: Imserso. Elaboración propia.

\subsubsection{Indicadores de coste: cálculo de las cuantías medias de las prestaciones económicas}

La cuantía media de las prestaciones económicas (Tabla 2) se ha calculado partiendo de las cuantías máximas establecidas en la disposición transitoria décima del Real Decreto-ley 20/2012, de 13 de julio, de medidas para garantizar la estabilidad presupuestaria y de fomento de la competitividad, con base en la tipología de prestación y el grado y nivel reconocido. Además, se han aplicado las fórmulas relativas a la aportación de la persona beneficiaria recogidas en el Acuerdo de Mejora del SAAD, publicado en el BOE por Resolución de 13 de julio de 2012, para determinar la cuantía concedida concreta de cada prestación. En todo caso, se ha tratado de ponderar el mayor número de factores posibles, en orden a calcular una cuantía media que se ajuste lo máximo posible a la realidad social y económica de las personas beneficiarias.

Tabla 2. Indicadores de coste: cuantía media de las prestaciones económicas

\begin{tabular}{|l|c|c|c|}
\cline { 2 - 4 } \multicolumn{1}{c|}{} & $\begin{array}{c}\text { Prestación } \\
\text { económica } \\
\text { vinculada al } \\
\text { servicio }\end{array}$ & $\begin{array}{c}\text { Prestación } \\
\text { económica para } \\
\text { cuidados en el } \\
\text { entorno familiar }\end{array}$ & $\begin{array}{c}\text { Prestación } \\
\text { económica } \\
\text { para } \\
\text { asistencia } \\
\text { personal }\end{array}$ \\
\hline $\begin{array}{l}\text { Cuantía } \\
\text { media }\end{array}$ & $569,19 € / \mathrm{mes}$ & $311,47 € / \mathrm{mes}$ & $605,12 € / \mathrm{mes}$ \\
\hline
\end{tabular}

Fuente: Imserso y SISAAD. Elaboración propia.

Los factores tenidos en cuenta para este cálculo han sido:

- Nivel de renta: 31 tramos, de acuerdo al servicio estadístico de la Seguridad Social eSTADISS ${ }^{6}$.

- Grados y niveles de dependencia: Grado III (sin nivel), Grado III nivel 2, Grado III nivel 1, Grado II (sin nivel), Grado II nivel 2, Grado II nivel I, Grado I (sin nivel) y Grado I nivel 2.

6 Véase 〈http://www.jubilacionypension.com/planes-fondos/ planes-pensiones/seguridad-social-estadiss-herramienta-conocerdatos-pensiones/>
- Categoría de prestación económica: vinculada al servicio, cuidados en el entorno familiar y asistencia personal.

La combinación de estos factores ha permitido contemplar los 744 escenarios posibles para la cuantía de las prestaciones, referidos en la Figura 2.

\subsubsection{Cálculo de las prestaciones de la Ley de Dependencia reconocidas para cada año}

El método de estimación se basa en la multiplicación del número de prestaciones por su coste. Para ello, se ha desarrollado un modelo de estimación que contempla las 934.316 prestaciones de 2012 , las 916.767 correspondientes a 2013 y las 898.332 de 2014, distinguiendo entre 33.728 escenarios -según la categoría de servicio o prestación, grado y nivel de dependencia, nivel de renta y comunidad autónoma de residencia-, así como 748 escenarios en el coste de las prestaciones - según la categoría de servicio o prestación, grado y nivel de dependencia, nivel de renta-. Para un mayor ajuste a la realidad, se han calculado medias móviles sobre la información disponible a 31 de diciembre de 2013. A continuación estas prestaciones se han puesto en relación con los indicadores de coste respectivos, esto es, con los costes medios de cada servicio y con las cuantías medias reconocidas de cada prestación económica, de manera que se pudiera llevar a cabo la multiplicación de cada servicio y prestación por su indicador.

Realizadas las operaciones expuestas anteriormente, se obtiene el resultado del coste de cada una de las tipologías de prestaciones del Sistema de Dependencia, para cada año, como se puede ver en el Gráfico 3 para el año 2014.

También se puede apreciar cómo el mayor coste se produce en los servicios y prestaciones ligados a un mayor grado de dependencia, como son la atención residencial (44,3\% del coste total) y las prestaciones económicas para cuidados en el entorno familiar ( $17 \%)$; mientras que servicios dirigidos a una dependencia moderada presentan un menor coste, a pesar de su extensión, como la teleasistencia (0,43\% del total). 
Tabla 3. Coste del Sistema de Dependencia, por comunidades autónomas. 2014

\begin{tabular}{|c|c|c|c|c|c|c|}
\hline & \multicolumn{2}{|c|}{ 2012: Coste del SAAD por CC.AA. } & \multicolumn{2}{|c|}{ 2013: Coste del SAAD por CC.AA. } & \multicolumn{2}{|c|}{ 2014: Coste del SAAD por CC.AA. } \\
\hline & & $\%$ s/total & & $\%$ s/total & & $\%$ s/total \\
\hline ANDALUCÍA & 1.612 .825 .567 & 23,4 & 1.477 .206 .140 & 21,5 & 1.393 .316 .783 & $19,7 \%$ \\
\hline ARAGÓN & 165.681 .861 & 2,4 & 149.420 .192 & 2,2 & 149.884 .333 & $2,1 \%$ \\
\hline ASTURIAS & 140.464 .171 & 2,0 & 138.061.499 & 2,0 & 136.832 .623 & $1,9 \%$ \\
\hline ISLAS BALEARES & 88.308 .768 & 1,3 & 84.893 .637 & 1,2 & 92.426 .661 & $1,3 \%$ \\
\hline CANARIAS & 116.562 .271 & 1,7 & 119.866 .808 & 1,7 & 126.830 .237 & $1,8 \%$ \\
\hline CANTABRIA & 127.547 .637 & 1,8 & 143.980 .243 & 2,1 & 151.727 .134 & $2,1 \%$ \\
\hline CASTILLA Y LEÓN & 558.562 .696 & 8,1 & 549.713 .540 & 8,0 & 548.564 .114 & $7,7 \%$ \\
\hline C. LA-MANCHA & 390.283 .406 & 5,7 & 400.770 .056 & 5,8 & 408.858 .819 & $5,8 \%$ \\
\hline CATALUÑA & 1.053 .099 .060 & 15,3 & 1.142 .166 .914 & 16,7 & 1.332 .740 .055 & $18,8 \%$ \\
\hline C. VALENCIANA & 460.950 .229 & 6,7 & 425.754 .250 & 6,2 & 403.766 .819 & $5,7 \%$ \\
\hline EXTREMADURA & 171.626 .079 & 2,5 & 182.736 .126 & 2,7 & 199.724 .056 & $2,8 \%$ \\
\hline GALICIA & 408.623 .017 & 5,9 & 439.275 .515 & 6,4 & 429.182 .559 & $6,1 \%$ \\
\hline C. DE MADRID & 892.281 .503 & 12,9 & 871.261 .203 & 12,7 & 912.984 .129 & $12,9 \%$ \\
\hline MURCIA & 185.089 .873 & 2,7 & 181.120 .781 & 2,6 & 208.099 .726 & $2,9 \%$ \\
\hline LA RIOJA & 81.011 .909 & 1,2 & 78.082 .674 & 1,1 & 75.249 .697 & $1,1 \%$ \\
\hline NAVARRA & 67.575 .599 & 1,0 & 70.112 .530 & 1,0 & 72.693 .055 & $1,0 \%$ \\
\hline PAÍS VASCO & 374.770 .285 & 5,4 & 403.245 .097 & 5,9 & 446.856 .125 & $6,3 \%$ \\
\hline TOTAL & 6.895 .263 .932 & 100,0 & 6.857 .667 .206 & $100,0 \%$ & 7.089 .736 .926 & $100,0 \%$ \\
\hline
\end{tabular}

Fuente: Imserso.

Esta misma operación se puede realizar por cada una de las comunidades autónomas y en cada uno de los años 2012 a 2014. Los resultados que obtenemos son los que se muestran en la Tabla 3, en la que podemos observar el mayor peso porcentual de Andalucía, Cataluña y la Comunidad de Madrid, como lógico trasunto de su mayor población absoluta, seguidas a cierta distancia por Catilla y León, Galicia y País Vasco, en las que el factor población de mayor edad presenta un mayor peso.

Finalmente, el coste total del Sistema de Dependencia en cada año se obtiene de la agregación de los sumandos de las prestaciones en cada año o de los costes de comunidad autónoma, con un coste total en torno a los 7.000 millones de euros para cada uno de los años, de acuerdo con el siguiente desglose:

- 2012: 6.895 millones de euros.

- 2013: 6.858 millones de euros

- 2014: 7.090 millones de euros.

Coincidentes con esta estimación de costes son tanto el Tribunal de Cuentas (2014), que lo cifra para el año 2012 en 7.084 millones de euros con información facilitada por las comunidades autónomas, como el 
estudio de Prada y Borge (2014), que lo calcula en 6.509 millones de $€$ en el año 2013.

\section{Financiación del Sistema de Dependencia}

Una vez determinado el coste de la Atención del SAAD, de conformidad con la metodología antes expuesta, se analiza a continuación la financiación y las aportaciones realizadas por las Administraciones públicas, Administración General del Estado y comunidades autónomas, así como las personas beneficiarias, de acuerdo con la legislación vigente aplicable al respecto.

\subsection{Financiación por la Administración General del Estado (AGE)}

Todas las aportaciones de la AGE para financiar el coste de Atención a la Dependencia se realizan a través de transferencias a las comunidades autónomas, ya sea por lo dispuesto en la Ley de Dependencia, o en virtud de lo dispuesto en la Ley $22 / 2009$, de 18 de diciembre, por la que se regula el sistema de financiación de las comunidades autónomas de régimen común y ciudades con estatuto de autonomía y se modifican determinadas normas tributarias, en adelante, Ley de financiación autonómica.

\subsubsection{Financiación estatal regulada en la Ley de Dependencia}

La Ley de Dependencia en su artículo 7 regula tres diferentes niveles de protección:

1ํㅡㄹ Nivel mínimo de protección: el establecido por la Administración General del Estado. Se asigna a las comunidades autónomas en función del número de personas beneficiarias con prestación reconocida, su grado de dependencia, así como la tipología de las prestaciones reconocidas?

Existe una estrecha relación entre la gestión llevada a cabo por las comunidades autónomas y los créditos que se transfieren como nivel mínimo: las cantidades que reciben las comunidades autónomas por este concepto dependen, en última instancia, de la cifra de personas beneficiarias con prestación reconocida existentes en cada comunidad, así como de su grado de dependencia reconocido. En consecuencia, un aumento en la cifra de personas beneficiarias con prestación

7 Real Decreto 1050/2013, de 27 de diciembre, por el que se regula el nivel mínimo de protección establecido en la Ley 39/2006, de 14 de diciembre, de Promoción de la Autonomía Personal y Atención a las personas en situación de dependencia (BOE nํㅜ 313, de 31 de diciembre de 2013). supondrá asimismo un aumento en las cantidades a transferir. En idéntico sentido, el reconocimiento de los mayores grados de dependencia (en especial el Grado III, Gran Dependencia) supondrá asimismo recibir unas mayores cantidades por este concepto, ya que los grados más elevados tienen asociadas unas cifras mayores en concepto de nivel mínimo. Por todo ello, las variaciones en la gestión realizada supondrán asimismo variaciones en las cantidades a transferir como nivel mínimo, de modo que un descenso tanto en la cantidad de personas beneficiarias, como en el reconocimiento de los grados más elevados, supondrá consecuentemente un descenso en la financiación por nivel mínimo.

2을 Nivel acordado: el que se acuerde entre la Administración General del Estado y la Administración de cada una de las comunidades autónomas a través de los Convenios previstos en el artículo 10 de la Ley de Dependencia. La disposición transitoria primera de la Ley establece su vigencia únicamente "durante el período comprendido entre el 1 de enero de 2007 y el 31 de diciembre de 2015, y para favorecer la implantación progresiva del Sistema”.

Desde la entrada en vigor de la Ley de Dependencia y hasta el año 2014, último ejercicio completo al redactar estas líneas, la Administración General del Estado, a través del Imserso, ha transferido a las comunidades autónomas 9.766 millones de euros en concepto de nivel mínimo y nivel acordado, como se detalla en la Tabla 5.

$3^{0} \quad$ Nivel adicional de protección: el que pueda establecer cada comunidad autónoma.

\subsubsection{Financiación estatal regulada en la Ley de financiación au tonómica}

Por lo que se refiere a las aportaciones llevadas a cabo en virtud de lo establecido en la Ley de Financiación Autonómica, desde la entrada en vigor de esta norma legal en 2009, la Administración General del Estado, a través del Ministerio de Hacienda, ha transferido a las comunidades autónomas 12.586 millones de euros en concepto de financiación adicional, tal y como se refleja en el Gráfico 3.

Se puede apreciar, como momento fundamental dentro de la evolución de la financiación del Sistema de Dependencia el ejercicio 2009, año en el que se comenzaron a transferir a las comunidades autónomas los créditos recogidos en la Ley de financiación autonómica.

Mediante esta vía de financiación, como recoge el Tribunal de Cuentas (2014), se han establecido 
créditos que, aunque formalmente sin carácter finalista, vienen a sufragar el mayor coste del SAAD para las comunidades autónomas. Además, estas cantidades se calculan precisamente con los mismos criterios con los que se calculaba el nivel acordado, es decir, teniendo en cuenta la población potencialmente dependiente y las personas dependientes con prestación. El Tribunal de Cuentas sostiene primero la procedencia de analizar estos fondos ${ }^{8}$, para después afirmar categóricamente que la financiación adicional no finalista es financiación de la dependencia ${ }^{9}$ y que tales créditos compensan la suspensión del nivel acordado en 2012, toda vez que las cifras asociadas a la financiación adicional superan las transferidas en concepto del mencionado nivel acordado ${ }^{10}$. 3.1.3. Financiación total de la dependencia por la
Administración General del Estado

De acuerdo con lo expuesto en los dos anteriores apartados, desde la entrada en vigor de la Ley de Dependencia en 2007 y hasta 2014 inclusive ${ }^{11}$, el Estado ha transferido a las comunidades autónomas un total de 22.352 millones de euros para la financiación de la dependencia, como se aprecia en el Gráfico 4, tanto por la vía finalista como por la adicional.

Durante el periodo correspondiente a este estudio, 2012 a 2014, la financiación estatal del Sistema de Dependencia, por vía finalista definida en la Ley

Gráfico 4. Financiación de la dependencia por la Administración General del Estado. 2007-2014 (en millones de euros)

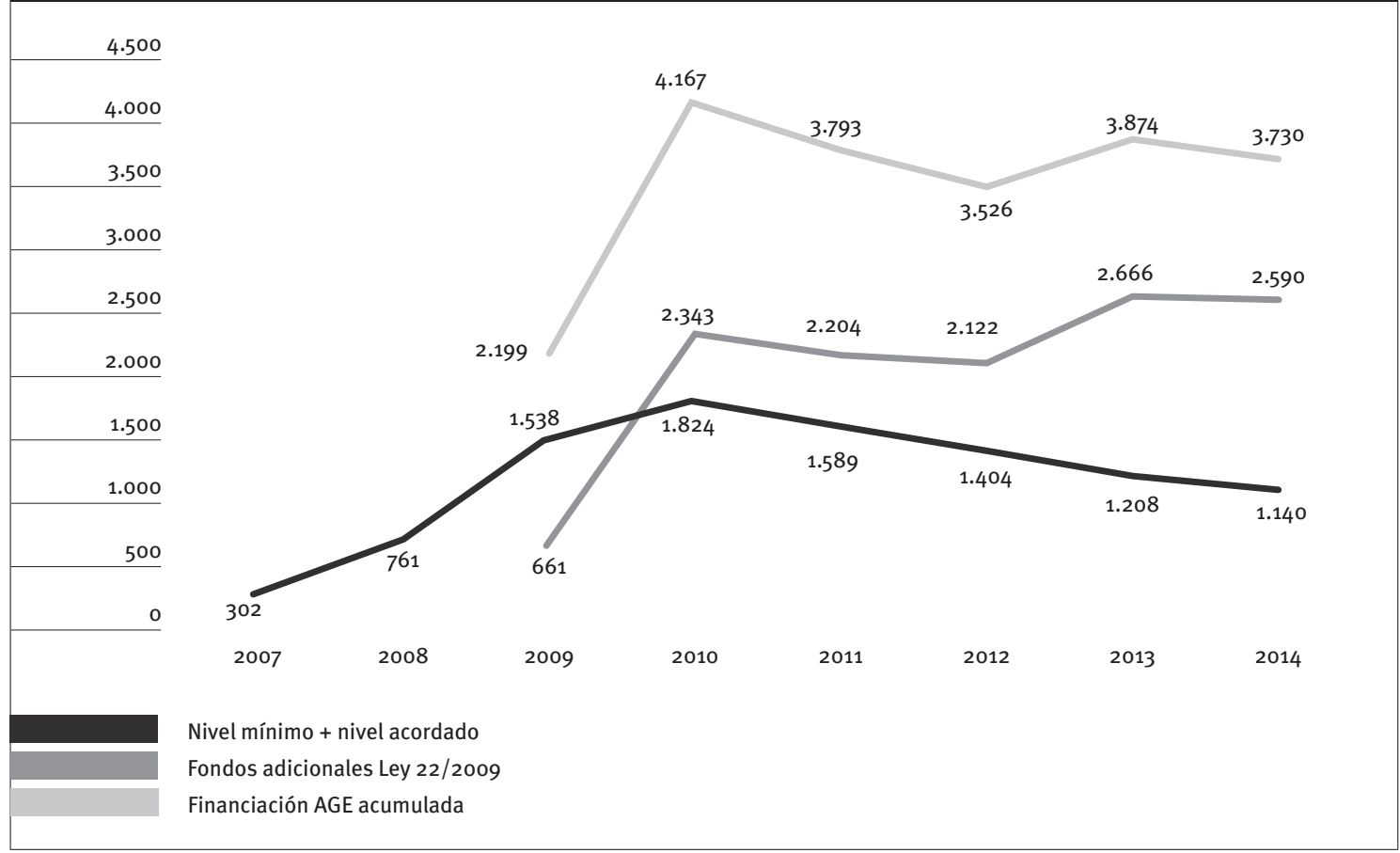

Fuente: Imserso, elaboración propia con base en los datos recogidos en el SISAAD, Presupuestos Generales del Estado y Tribunal de Cuentas.

8 "La referencia a los recursos adicionales, cuya distribución viene exclusiva y directamente vinculada al sistema de dependencia, resulta necesaria para determinar de manera completa la financiación total obtenida por las comunidades autónomas en relación con dicho sistema" (Tribunal de Cuentas, Informe de fiscalización 1.035/2014, pág. 62).

9 "La financiación específica de la dependencia está constituida por el nivel mínimo de protección, a cargo del Imserso, que representó el $19,71 \%$ del total. Para el resto de aportación realizada por las comunidades autónomas, éstas recibieron del estado a través de los recursos adicionales no finalistas, si bien directamente vinculados al número de dependientes previstos en la Ley $22 / 2009$, un importe que representó el $29,52 \%$ del total, siendo el 50,77\% restante financiado por las comunidades autónomas a través de otros recursos públicos propios" (Tribunal de Cuentas, Informe de fiscalización 1.035/2014, pág. 83).

${ }_{10}$ "Por todo lo anterior, resulta evidente la correlación existente entre los recursos del nivel acordado suspendidos y los recursos adicionales incrementados, atendiendo a la finalidad de ambos, y a su cálculo conforme a unos mismos criterios, sin que ello implique el mismo carácter de financiación afectada" (Tribunal de Cuentas, Informe de fiscalización 1.035/2014).
${ }^{11}$ En este cálculo se ha tenido en cuenta las cantidades que corresponderían tanto a la Comunidad Autónoma del País Vasco como a la Comunidad Foral de Navarra, a través de la aplicación de los correspondientes porcentajes establecidos en la normativa especial sobre sus regímenes financieros (un 6,24\% de acuerdo con el Concierto Económico entre el Estado y la Comunidad Autónoma de País Vasco, y un $1,60 \%$ de conformidad con el Convenio Económico entre el Estado y la Comunidad Foral de Navarra). 
de Dependencia y por la vía adicional de la Ley de financiación autonómica, ha sido de 11.130 millones de euros, con el detalle que se muestra en la Tabla 4.

Tabla 4. Financiación estatal del coste del Sistema de Dependencia. 2012-2014 (en millones de euros)

\begin{tabular}{|l|c|c|c|}
\cline { 2 - 4 } \multicolumn{1}{c|}{} & 2012 & 2013 & 2014 \\
\hline $\begin{array}{l}\text { Fondos finalistas Ley } \\
\text { Dependencia }\end{array}$ & 1.404 & 1.208 & 1.140 \\
\hline $\begin{array}{l}\text { Fondos adicionales Ley } \\
\text { financiación autonómica }\end{array}$ & 2.122 & 2.666 & 2.590 \\
\hline Total financiación estatal & $\mathbf{3 . 5 2 6}$ & $\mathbf{3 . 8 7 4}$ & $\mathbf{3 . 7 3 0}$ \\
\hline
\end{tabular}

Fuente: Imserso, elaboración propia con base en los datos recogidos en el SISAAD, Presupuestos Generales del Estado y Tribunal de Cuentas.

\subsection{Financiación de la dependencia por las comunidades autónomas}

Corresponde a las comunidades autónomas planificar, ordenar, coordinar, dirigir y gestionar, en el ámbito de su territorio, los servicios y recursos necesarios para la atención de la dependencia, tal como señala el artículo 11 de la Ley de Dependencia.

Además, esta Ley establece en su artículo 32 que “la financiación del Sistema será la suficiente para garantizar el cumplimiento de las obligaciones que correspondan a las Administraciones Públicas competentes y se determinará anualmente en los correspondientes Presupuestos" y que "la aportación de la Comunidad Autónoma será, para cada año, al menos igual a la de la Administración General del Estado". Es decir, de este precepto se deriva la obligación de las comunidades autónomas de aportar cada año una cantidad igual a la recibida por parte de la AGE.

No obstante, no resulta sencillo conocer con exactitud las aportaciones realizadas por las comunidades autónomas para la financiación del SAAD, toda vez que en sus respectivos presupuestos no se recogen de manera específica partidas destinadas a la atención a la dependencia. Tales cantidades suelen venir recogidas en las mismas partidas donde se consignan créditos relativos a otros conceptos de servicios sociales, como la atención a las personas mayores, a las personas con discapacidad, o a los servicios sociales básicos. Es más, en el marco de las transferencias que se realizan por parte de las comunidades autónomas a las Entidades Locales, o a Entidades sin ánimo de lucro, tampoco resulta posible realizar esta diferenciación.

Esta dificultad ha sido puesta de manifiesto igualmente por el propio Tribunal de Cuentas (2014) al afirmar que:

Las comunidades autónomas no han establecido en su ámbito presupuestario, una nítida separación entre los créditos establecidos para la atención de la dependencia y los previstos para los restantes servicios sociales. Asimismo, carecen de sistemas de contabilidad analítica aplicable a los gastos de dependencia y, en su gran mayoría tampoco han dispuesto los instrumentos contables necesarios para efectuar el seguimiento contable de estos gastos, en su consideración de financiación afectada, lo que les impide certificar con exactitud el importe total de los recursos destinados a la dependencia ${ }^{12}$.

En tanto que las comunidades autónomas se doten de los "sistemas de contabilidad analítica, que serían necesarios para cuantificar con exactitud el coste de la dependencia, con separación de otros costes de servicios sociales que proporcionan a la ciudadanía" que reclama en su Informe, el Tribunal de Cuentas recaba la información disponible y concluye con el reparto de financiación pública entre Estado $(49,23 \%)$ y comunidades autónomas $(50,77 \%)$ que se reproduce en el Gráfico 5, imagen fiel del recogido por el Tribunal de Cuentas en su Informe, en el que se aprecia que, tal y como obliga la Ley de Dependencia, la aportación global del Estado y las del conjunto de las Administraciones autonómicas, en 2012, según el Tribunal de Cuentas fueron prácticamente equivalentes.

Gráfico 5. Financiación del Sistema de Dependencia. $2012(\%)$

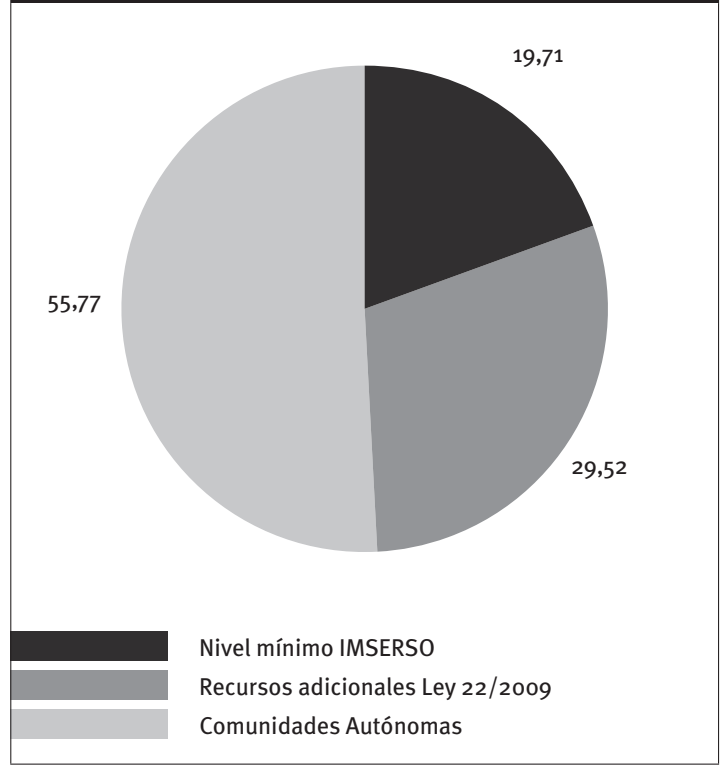

Fuente: Tribunal de Cuentas (2014). Gráfico II.4·3-1.

${ }^{12}$ Al referirse a la aportación de los beneficiarios el Tribunal de Cuentas añade que "los sistemas contables establecidos actualmente tampoco permiten cuantificar con exactitud la aportación de los beneficiarios al coste total de la dependencia”. No obstante, sí que aclara el Tribunal que "a la aportación que efectúa la AGE en concepto de nivel mínimo de protección, y en su caso, de nivel acordado, con los correspondientes créditos claramente identificados en los Presupuestos Generales del Estado, no le afectan las dificultades para su determinación que sí afectan a las otras fuentes de financiación". 
Aplicando la lógica del Tribunal de Cuentas, se pueden establecer por diferencia las aportaciones de las comunidades autónomas que, en el periodo 2012-2014, habrían sido un total de 9.711 millones de euros, de acuerdo con el siguiente desglose anual:

- 2012: 3.369 millones de euros.

- 2013: 2.984 millones de euros.

- 2014: 3.360 millones de euros.

Sin embargo, quedaría aún por determinar lo que significan en estas cantidades las aportaciones de los beneficiarios de la Ley de Dependencia.

\subsection{Participación de las personas beneficiarias en la financiación del Sistema}

La Ley de Dependencia establecía, ya en 2006, que, además de las aportaciones de las diferentes Administraciones públicas, las personas beneficiarias participen asimismo en la financiación de las prestaciones que reciben ${ }^{13}$ con un tercio del coste total del Sistema. Estas previsiones fueron desarrolladas y concretadas por el Acuerdo del Consejo Territorial de de Servicios Sociales y del SAAD para la mejora del Sistema para la Autonomía y Atención a la Dependencia, de 10 de julio de $2012^{14}$, mediante el que se fijaron los criterios y contenidos sobre capacidad económica y participación del beneficiario en el coste de las prestaciones del Sistema, cuando proceda. De este modo, se han establecido criterios de procedencia o no de esa participación. Los conceptos que deberán tenerse en cuenta a la hora de determinar la capacidad económica del beneficiario son, principalmente, renta y patrimonio, de los que dependerá la determinación de su participación en la financiación de las prestaciones que recibe. Este hecho puede ayudar a situar en sus justos términos el debate sobre la participación de los beneficiarios en la financiación del coste del Sistema de Dependencia, ya que esta participación no es de carácter absoluto, sino que tiene límites y su procedencia o no se determina en función de la capacidad económica de la persona.

${ }^{13} \mathrm{El}$ art. 33 de la Ley de Dependencia dispone lo siguiente:

1. Los beneficiarios de las prestaciones de dependencia participarán en la financiación de las mismas, según el tipo y coste del servicio y su capacidad económica personal.

2. La capacidad económica del beneficiario se tendrá también en cuenta para la determinación de la cuantía de las prestaciones económicas.

3. El Consejo Territorial del Sistema para la Autonomía y Atención a la Dependencia fijará los criterios para la aplicación de lo previsto en este artículo, que serán desarrollados en los Convenios a que se refiere el artículo 10. Para fijar la participación del beneficiario, se tendrá en cuenta la distinción entre servicios asistenciales y de manutención y hoteleros.

4. Ningún ciudadano quedará fuera de la cobertura del Sistema por no disponer de recursos económicos.

${ }_{14}$ Publicado por Resolución de 13 de julio de 2012 de la Secretaría de Estado de Servicios Sociales e Igualdad (BOE no 185 , de 3 de agosto).
De una lectura sistemática de la Ley de Dependencia y del Acuerdo del Consejo Territorial, se desprende la existencia de dos garantías para las personas beneficiarias:

- En primer lugar, una garantía “de mínimos”, que supone que ninguna persona se quedará excluida del Sistema de Dependencia por falta de recursos, lo que se traduce en que aquellas personas cuyos ingresos no alcanzan una determinada cuantía, por lo común el Indicador Público de Rentas de Efectos Múltiples (IPREM), no participarán en la financiación de sus prestaciones, de modo que no realizarán aportación alguna.

- Y, en segundo lugar, una garantía “de máximos”, que supone que, en todo caso, y por muy elevada que pueda resultar la capacidad económica de una persona beneficiaria, ésta aportará, como cuantía tope, el $90 \%$ del servicio que reciba, sin que en ningún momento financie la totalidad de la correspondiente prestación.

De un modo similar a lo manifestado a propósito de las aportaciones de las comunidades autónomas, el Tribunal de Cuentas ha señalado en su Informe de fiscalización 1.035/2014 la dificultad existente a la hora de poder determinar las cantidades aportadas por las personas beneficiarias, al afirmar en su página 81 , que "no resulta posible cuantificar ni siquiera de forma aproximada la participación en la financiación que efectúan a través del copago los propios beneficiarios".

En todo caso, la nueva normativa sobre el nivel mínimo recogida en el citado Real Decreto 1050/2013, de 27 de diciembre, ha incorporado la obligación de las comunidades autónomas de aportar anualmente un certificado donde se recoja el gasto realizado en la materia. De este modo, a partir de las mencionadas certificaciones se podrá conocer con una mayor precisión las cantidades aportadas por las comunidades autónomas. En esta misma línea, el mencionado Real Decreto y la nueva Orden reguladora del SISAAD establecen la obligación para las comunidades autónomas de incluir la aportación de los beneficiarios como dato obligatorio en el Sistema, de tal manera que en el futuro se podrá conocer esta información.

Con el fin de contar con información al respecto, en el Imserso se ha realizado un ejercicio de cálculo de estas aportaciones, estimando la capacidad económica de las personas beneficiarias con base en los datos económicos de las mismas (tramos de rentas medias, pensiones, etc...) y aplicando los criterios de determinación de la aportación de la persona beneficiaria para cada servicio o prestación, en función de su capacidad económica, contenidos en el Acuerdo del Consejo Territorial de Servicios Sociales y del SAAD de 2012 antes referido. La estimación de las aportaciones de los beneficiarios, obtenida para el periodo objeto 2012-2014, ha sido de 5.691 millones de euros, de acuerdo con el siguiente desglose por años: 
- 2012: 1.848 millones de euros. Un 26,8\% del total.

- 2013: 1.947 millones de euros. Un 28,4 \% del total.

- 2014: 1.896 millones de euros. Un 26,7\% del total.

En unas cifras bastante similares se encuentra el estudio realizado por Prada y Borge (2014) en el que, como se aprecia en el Gráfico 6, para el ejercicio 2013 estimaron una cantidad de 1.870 millones de $€$ en concepto de aportación de los beneficiarios, un $28,73 \%$ del total. Para ello, siguieron una metodología similar a la utilizada en el Imserso, teniendo en cuenta diferentes tramos de renta de las personas beneficiarias.

Gráfico 6. Aportación de los beneficiarios al coste total de la dependencia. 2013 (\%)

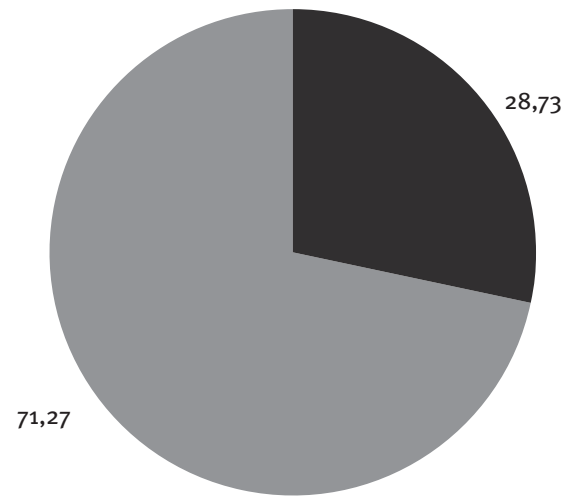

Aportación usuario

Aportación administración

Fuente: Prada y Borge (2014).

3.4. Financiación global de la dependencia: aportaciones de la Administración General del Estado, de las comunidades autónomas y de los beneficiarios.

Llegados a este punto se pueden presentar ya los cálculos de la financiación del coste de la dependencia realizados. En la Tabla 5 se muestran los resultados, teniendo en cuenta los tres sumandos anteriormente expuestos:

- La aportación de la Administración General del Estado: tanto la financiación finalista del nivel mínimo de protección estatal derivada de la Ley de Dependencia, como la financiación adicional no finalista derivada de la Ley de Financiación de las Comunidades Autónomas de Régimen Común, así como el cálculo correspondiente a las comunidades de régimen especial (País Vasco y Navarra).
- La aportación de recursos propios de las comunidades autónomas: estimación obtenida por diferencia con las aportaciones del Estado y de los beneficiarios.

- La aportación de los beneficiarios: estimada a partir de su capacidad económica.

Tabla 5. Estimación de la financiación del coste del Sistema de Dependencia. 2012-2014 (en millones de euros)

\begin{tabular}{|l|c|c|c|}
\cline { 2 - 4 } \multicolumn{1}{l|}{} & 2012 & 2013 & 2014 \\
\hline $\begin{array}{l}\text { Administración General del } \\
\text { Estado }\end{array}$ & 3.526 & 3.874 & 3.730 \\
\hline $\begin{array}{l}\text { Comunidades autónomas } \\
\text { recursos propios }\end{array}$ & 1.521 & 1.037 & 1.464 \\
\hline Beneficiarios & 1.848 & 1.947 & 1.896 \\
\hline $\begin{array}{l}\text { TOTAL FINANCIACIÓN COSTE } \\
\text { DEPENDENCIA }\end{array}$ & 6.895 & 6.858 & 7.090 \\
\hline
\end{tabular}

Fuente: Imserso. Elaboración propia.

En la Tabla 5 resulta apreciable cómo las aportaciones realizadas por cada una de las tres partes, durante los años 2012 a 2014 en los que nos detenemos en este estudio, fueron distintas a las previstas por la Ley de Dependencia y su Memoria de Impacto:

- La aportación de la Administración General del Estado a la financiación de la atención a la dependencia, supuso más del tercio del coste total del Sistema previsto en la Memoria de Impacto de la Ley de Dependencia. Para el ejercicio 2012 las aportaciones de la AGE supusieron el $51,1 \%$ del coste total; en el año 2013 un 56,5\% y en el año 2014 un 52,61\%.

- Las estimaciones de las aportaciones de recursos propios de las comunidades autónomas estuvieron por debajo de la financiación del Estado y de las previsiones de la Memoria de Impacto de la Ley de Dependencia: un $22,1 \%$ en 2012, un $15,1 \%$ en 2013 y un $20,64 \%$ en 2014 .

- La estimación de las aportaciones de los mismos beneficiarios se acercan a las previsiones iniciales de la Ley de Dependencia y de su Memoria: un $26,8 \%$ en $2012,28,4 \%$ en 2013 y $26,75 \%$ en 2014 .

Finalmente, el estudio de estas diversas vías de financiación puede realizarse para cada una de las comunidades autónomas y por cada uno de los años 2012 a 2014. En la Tabla 6 de este trabajo se recoge la distribución de las aportaciones para la financiación del coste del SAAD por comunidades autónomas, tan solo para el último ejercicio objeto de estudio en este artículo por razones de espacio y dado que los valores tanto absolutos como relativos son muy estables a lo largo del periodo estudiado, ya que, como vimos al principio de este trabajo, la cifra de beneficiarios atendidos por el Sistema de Dependencia de 2012 a 2014 se ha mantenido bastante estable en torno a las 750.000 personas. 
Tabla 6. Detalle de la estimación de la financiación del coste del Sistema de Dependencia, por comunidades autónomas. 2014

\begin{tabular}{|c|c|c|c|c|c|c|c|c|c|c|c|}
\hline \multirow{2}{*}{$\begin{array}{l}\text { Coste } 2014 \\
\text { CC.AA } \\
\text { régimen } \\
\text { común }\end{array}$} & \multirow{2}{*}{$\begin{array}{c}\text { Coste de la } \\
\text { dependencia }\end{array}$} & \multicolumn{6}{|c|}{ Aportación AGE } & \multicolumn{2}{|c|}{$\begin{array}{c}\text { Aportación del } \\
\text { beneficiario }\end{array}$} & \multicolumn{2}{|l|}{ CC.AA. } \\
\hline & & Fin. finalista & $\%$ & $\begin{array}{c}\text { Fdos. } \\
\text { Adicionales }\end{array}$ & $\%$ & Total AGE & $\%$ & & $\%$ & $\begin{array}{c}\text { Como } \\
\text { diferencia }\end{array}$ & $\%$ \\
\hline Andalucía & 1.393 .316 .783 & 252.156 .060 & 18 & 592.092 .685 & 42 & 844.248 .745 & 61 & 333.679 .441 & 24 & 215.388 .597 & 15 \\
\hline Aragón & 149.884 .333 & 28.290 .674 & 19 & 98.783 .309 & 66 & 127.073 .983 & 85 & 40.237 .856 & 27 & -17.427 .507 & -12 \\
\hline Asturias & 136.832 .623 & 24.902 .549 & 18 & 73.364 .539 & 54 & 98.267 .088 & 72 & 49.156.170 & 36 & -10.590 .634 & -8 \\
\hline $\begin{array}{l}\text { Islas } \\
\text { Baleares }\end{array}$ & 92.426 .661 & 19.236 .454 & 21 & 50.919 .868 & 55 & 70.156 .322 & 76 & 20.133 .306 & 22 & 2.137 .033 & 2 \\
\hline Canarias & 126.830 .237 & 25.085 .448 & 20 & 61.159 .413 & 48 & 86.244 .861 & 68 & 33.320 .100 & 26 & 7.265 .276 & 6 \\
\hline Cantabria & 151.727 .134 & 18.064 .836 & 12 & 42.903 .179 & 28 & 60.968 .015 & 40 & 50.205 .329 & 33 & 40.553 .791 & 27 \\
\hline $\begin{array}{l}\text { Castilla y } \\
\text { León }\end{array}$ & 548.564 .114 & 89.678 .070 & 16 & 160.961 .531 & 29 & 250.639 .601 & 46 & 121.935 .652 & 22 & 175.988 .861 & 32 \\
\hline Cataluña & 1.332 .740 .055 & 185.527 .440 & 14 & 427.086 .791 & 32 & 612.614 .231 & 46 & 300.631 .244 & 23 & 419.494 .580 & 31 \\
\hline C. Valenciana & 403.766 .819 & 60.265 .259 & 15 & 181.924 .298 & 45 & 242.189 .557 & 60 & 100.609 .489 & 25 & 60.967 .774 & 15 \\
\hline Extremadura & 199.724 .056 & 36.976 .378 & 19 & 71.841 .471 & 36 & 108.817 .849 & 54 & 38.548 .858 & 19 & 52.357 .349 & 26 \\
\hline Galicia & 429.182.559 & 64.767 .341 & 15 & 175.255 .730 & 41 & 240.023 .071 & 56 & 95.890 .631 & 22 & 93.268 .857 & 22 \\
\hline C. de Madrid & 912.984 .129 & 144.231 .136 & 16 & 206.499 .206 & 23 & 350.730 .342 & 38 & 354.797 .336 & 39 & 207.456 .452 & 23 \\
\hline Murcia & 208.099 .726 & 53.425 .460 & 26 & 85.898 .977 & 41 & $139 \cdot 324.437$ & 67 & 30.606 .872 & 15 & 38.168 .417 & 18 \\
\hline La Rioja & 75.249 .697 & 12.219 .325 & 17 & 28.588 .398 & 0 & 12.219 .325 & 17 & 22.780 .985 & 31 & 37.692 .745 & 52 \\
\hline TOTAL & 6.570 .187 .746 & 1.075 .279 .065 & 16,4 & 2.401 .806 .199 & 36,6 & 3.448 .496 .866 & 52,5 & 111.704 .460 .392 & 25,9 & 1.414 .673 .846 & 21,5 \\
\hline
\end{tabular}

\begin{tabular}{|c|c|c|c|c|c|c|c|c|c|c|c|}
\hline \multirow{2}{*}{$\begin{array}{l}\text { Coste } 2014 \\
\text { País Vasco y } \\
\text { Navarra }\end{array}$} & \multirow{2}{*}{$\begin{array}{c}\text { Coste de la } \\
\text { dependencia }\end{array}$} & \multicolumn{6}{|c|}{ Aportación AGE } & \multicolumn{2}{|c|}{$\begin{array}{c}\text { Aportación del } \\
\text { beneficiario }\end{array}$} & \multicolumn{2}{|c|}{ CC.AA. } \\
\hline & & Fin. finalista & $\%$ & $\begin{array}{l}\text { Estimación } \\
\text { financiación } \\
\text { adicional }\end{array}$ & $\%$ & Total AGE & $\%$ & & $\%$ & $\begin{array}{c}\text { Como } \\
\text { diferencia }\end{array}$ & $\%$ \\
\hline Navarra & 72.693 .055 & 12.219 .325 & 16,6 & 37.971 .485 & 52,2 & 50.190 .810 & 69,0 & 22.780 .985 & 31,3 & -278.740 & $-0,4$ \\
\hline País Vasco & 446.856 .125 & 54.663 .569 & 12,2 & 148.088 .791 & 33,1 & 202.752 .360 & 45,4 & 172.804 .481 & 38,7 & 71.299 .283 & 16,0 \\
\hline TOTAL & 519.549 .180 & 66.882 .894 & 12,9 & 186.060 .276 & 35,8 & 252.943 .170 & 48,7 & 195.585 .467 & 37,6 & 71.020 .544 & 13,7 \\
\hline
\end{tabular}

\begin{tabular}{|c|c|c|c|c|c|c|c|c|c|c|c|}
\hline $\begin{array}{l}\text { Coste } \\
2014 \\
\end{array}$ & \multirow{2}{*}{$\begin{array}{c}\text { Coste de la } \\
\text { dependencia }\end{array}$} & \multicolumn{6}{|c|}{ Aportación AGE } & \multicolumn{2}{|c|}{$\begin{array}{c}\text { Aportación del } \\
\text { beneficiario }\end{array}$} & \multicolumn{2}{|l|}{ CC.AA. } \\
\hline $\begin{array}{l}\text { Total } \\
\text { CC.AA. }\end{array}$ & & Fin. finalista & $\%$ & $\begin{array}{c}\text { Fdos. } \\
\text { Adicionales }\end{array}$ & $\%$ & Total AGE & $\%$ & & $\%$ & $\begin{array}{c}\text { Como } \\
\text { diferencia }\end{array}$ & $\%$ \\
\hline TOTAL & 7.089 .736 .926 & 1.142 .161 .960 & 16,1 & 2.590 .107 .805 & 36,5 & 252.943 .170 & 48,7 & 1.900 .045 .858 & 26,8 & 1.483 .453 .060 & 20,9 \\
\hline
\end{tabular}

Fuente: Imserso. Elaboración propia.

El Tribunal de Cuentas (2014) ya puso de relieve que, por parte de la AGE, se estaba cumpliendo el mandato legalmente establecido de financiar, al menos, la mitad del coste del Sistema.

En el Gráfico 8 de este estudio se recoge la representación gráfica que realiza el Tribunal, en el Informe de fiscalización citado, de los porcentajes reales de las aportaciones autonómicas, en las Comunidades de régimen común, a la financiación de la dependencia certificadas, esto es muy relevante, por las propias Administraciones autonómicas. Es decir, el Tribunal de Cuentas afirma, con información de las propias comunidades autónomas, que estas -junto con los beneficiarios- se encuentran aportando entre el $73 \%$ de la financiación total del Sistema (Madrid) y el $27 \%$ (Galicia). De este modo, con base en la información facilitada por las propias comunidades autónomas al Tribunal de
Cuentas, durante el año 2012 las aportaciones de la AGE alcanzaron una media del 59,23\% del coste total, mientras que las aportaciones de las CC.AA. (incluidas las aportaciones de los beneficiarios), supusieron el $50,77 \%$.

Y por último, debe así mismo reseñarse que el estudio de Prada y Borge (2014) llega a unas conclusiones similares, puesto que en el mismo se recoge que para el ejercicio 2013 las aportaciones efectuadas por la AGE alcanzaron el $54,77 \%$ del coste total de la atención a la dependencia, mientras que las aportaciones de los presupuestos autonómicos supondrían tan sólo el 16,50\%, y las aportaciones de los beneficiarios serían de un $28,73 \%$, como se puede apreciar en el Gráfico 9.

Como se ha podido contemplar, el modelo de financiación del Sistema de Dependencia que se 


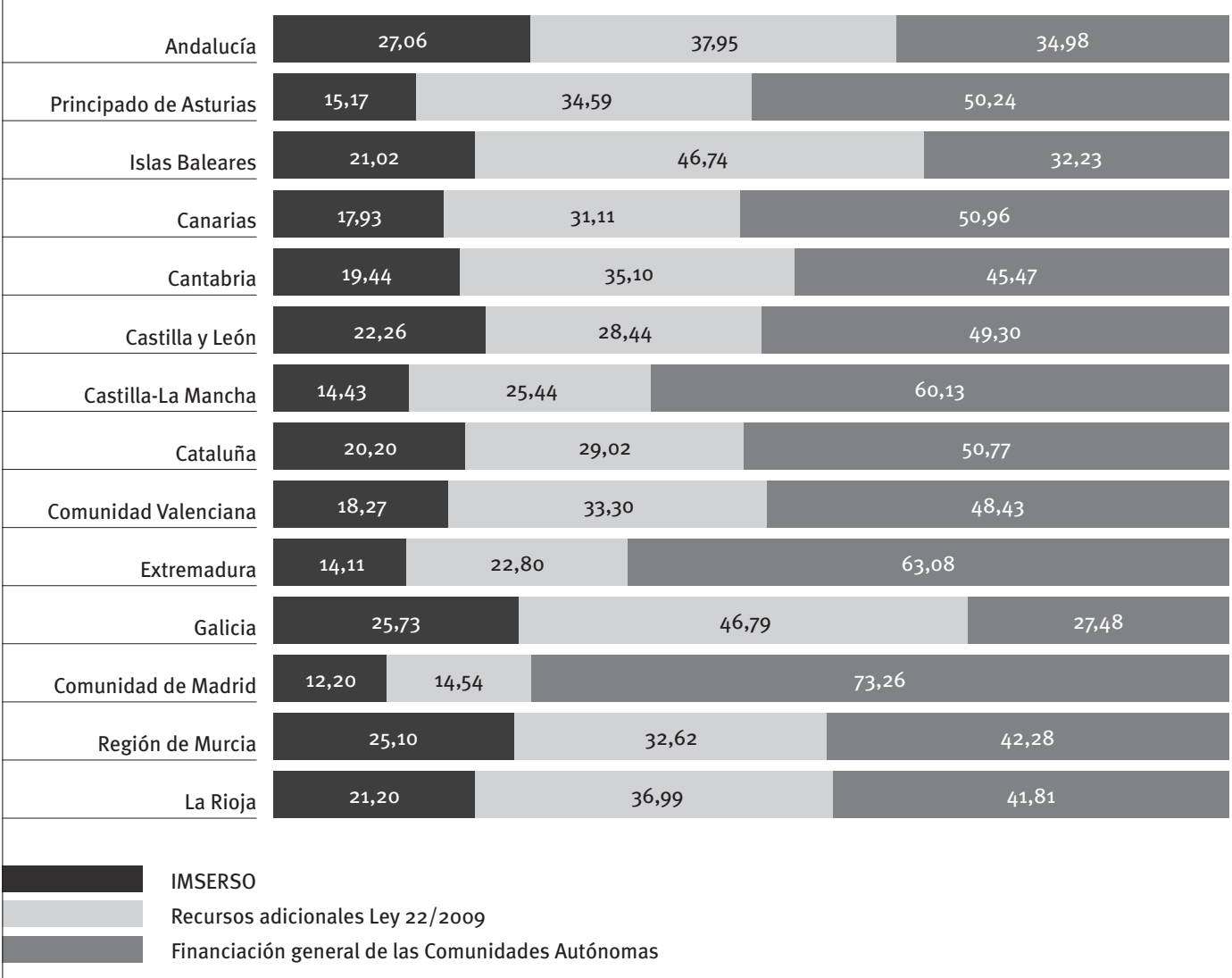

Fuente: Tribunal de Cuentas, 2014. Gráfico II.4.3-2.

\section{Gráfico 8. Financiación de la dependencia. 2013 (\%)}

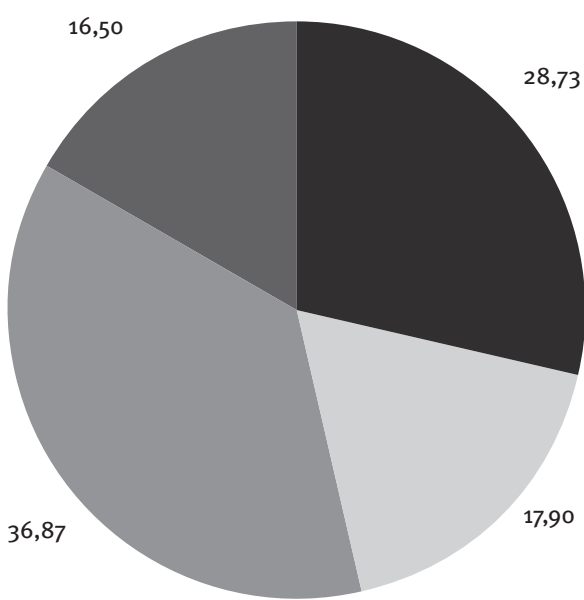

Beneficiarios

Nivel mínimo

Financiación adicional

Comunidades Autónomas ha ido construyendo desde la entrada en vigor de la Ley de Dependencia y, en especial, a partir de 2009 con la aparición de los fondos adicionales no finalistas, quizá peque de excesiva complejidad. Para simplificar esta complejidad, pudiera ser conveniente evolucionar este modelo de financiación hacia una unificación de las dos vías de financiación estatal en una sola, lo que contribuiría a clarificar las distintas aportaciones a la financiación del coste de la atención a la dependencia.

\section{Conclusiones}

Para cerrar este artículo, podemos concretar ya las principales conclusiones que se han ido apuntando a lo largo del mismo.

1. La Memoria de Análisis de Impacto de la Ley de Dependencia estimó el coste del Sistema de Dependencia en 2015 en 9.355 millones de euros, que serían aportados en partes similares por la Administración General de Estado (3.101,5 millones), las comunidades autónomas (3.101,5 millones) y los beneficiarios (3.153 millones).

2. El coste del Sistema de Dependencia en cada uno de los años del periodo 2012-2014 habría sido: 
- 2012: 6.895 millones de euros.

- 2013: 6.858 millones de euros.

- 2014: 7.090 millones de euros.

3. La financiación de este coste se realiza por el Estado, las comunidades autónomas y los propios beneficiarios.

4. La financiación del Estado se rige por dos vías distintas: finalista y adicional o no finalista, reguladas por sendas Leyes que garantizan las aportaciones a realizar por parte del Estado a las comunidades autónomas para financiar el coste de atención a la dependencia:

- La Ley de Dependencia, la financiación finalista, a través del nivel mínimo de protección y, en su caso, del nivel acordado.

- La Ley de financiación autonómica, de carácter no finalista, que viene a sufragar el mayor coste del Sistema de Dependencia para las comunidades autónomas y que se calcula, precisamente, con los mismos criterios con los que se calculaba el nivel acordado, es decir, teniendo en cuenta la población potencialmente dependiente y las personas dependientes con prestación.
5. Durante todo el período de vigencia de la Ley de Dependencia, 2007-2014, la Administración General del Estado ha destinado a las comunidades autónomas 22.352 millones de euros, tanto por la vía finalista como por la adicional o no finalista.

6. En el periodo 2012-2014, objeto de este estudio, la Administración General del Estado ha destinado a las comunidades autónomas 11.130 millones de euros, tanto por la vía finalista como por la no finalista.

7. En concreto, en 2014, último ejercicio completo del que se disponen cifras, se han transferido por el Estado a las comunidades autónomas 3.730 millones de euros. Esta cantidad supone el 52,61\% del coste anual del Sistema de Dependencia. El resto habría sido financiado por comunidades autónomas (20,64\%) y beneficiarios (26,75\%). En el resto de años del periodo 2012-2014 esta distribución relativa ha resultado muy similar.

8. Parece conveniente evolucionar este modelo de financiación del Sistema de Dependencia hacia una unificación de las dos vías estatales de financiación. 
ASOCIACIÓN ESTATAL DE DIRECTORAS Y GERENTES DE SERVICIOS SOCIALES (2012): "Demolición controlada de la Ley de Dependencia”, Málaga, 28-12-12.

ESPAÑA (2013): “Real Decreto 1050/2013, de 27 de diciembre, por el que se regula el nivel mínimo de protección establecido en la Ley 39/2006, de 14 de diciembre, de Promoción de la Autonomía Personal y Atención a las personas en situación de dependencia", Boletín Oficial del Estado, no 313, 31-12-13, págs. 107.120 ss.

- (2012): "Real Decreto-ley 20/2012, de 13 de julio, de medidas para garantizar la estabilidad presupuestaria y de fomento de la competitividad", Boletín Oficial del Estado, $\mathrm{n}$ $168,14-7-12$, págs. 50.428 ss.

- (2012): “Resolución de 13 de julio de 2012, de la Secretaría de Estado de Servicios Sociales e Igualdad, por la que se publica el Acuerdo del Consejo Territorial del Sistema para la Autonomía y Atención a la Dependencia para la mejora del sistema para la autonomía y atención a la dependencia”, Boletín Oficial del Estado, 3-8-12, no 185 , págs. 55.657 ss.

- (2009): Ley 22/2009, de 18 de diciembre, por la que se regula el sistema de financiación de las Comunidades Autónomas de régimen común y Ciudades con Estatuto de Autonomía y se modifican determinadas normas tributarias", Boletín Oficial del Estado, 19-12-09, n- 305, págs. $107.087 \mathrm{~s}$.

- (2006): “Ley 39/2006, de 14 de diciembre, de Promoción de la Autonomía Personal y Atención a las personas en situación de dependencia", Boletín Oficial del Estado, nํ299, 15-12-06, págs. $44.142 \mathrm{ss}$.

IMSERSO (2015): Avance de la Evaluación anual del ejercicio 2014 de los resultados de la aplicación de la Ley de Dependencia, Madrid.
- (2015): Servicios sociales dirigidos a personas mayores en España. Diciembre de 2012, Madrid.

- (2014): Evaluación anual ejercicio 2013 de los resultados de aplicación de la Ley de Dependencia, Madrid.

- (2013): Evaluación anual ejercicio 2012 de los resultados de aplicación de la Ley de Dependencia, Madrid.

- (2012): Evaluación de resultados a 1 de enero de 2012 de la Ley de Dependencia, Madrid.

MINISTERIO DE TRABAJO Y ASUNTOS SOCIALES (2006): Memoria del análisis de impacto normativo, económico, de género e igualdad de oportunidades, no discriminación y accesibilidad universal. Anteproyecto de Ley de Promoción de la Autonomía Personal y de Atención a las personas en situación de dependencia, Madrid.

MONTSERRAT, J. (2013): "La Ley de Dependencia, en caída libre”, Agathos: Atención Sociosanitaria y Bienestar, no 2, págs. 62-64.

MORÁN, C. (2010): “No sólo falta dinero para dependencia, falta control", El País, 2-5-10.

PRADA, M. D.; y BORGE, L. M. (2014): Una aproximación al coste de la dependencia en España y su financiación, Universidad de Valladolid.

TRIBUNAL DE CUENTAS (2014): Informe de fiscalización sobre las medidas de gestión y control adoptadas por las comunidades autónomas para la adecuada aplicación de la Ley 39/2006, de 14 de diciembre, de Promoción de la Autonomía Personal y Atención a la Dependencia, Madrid.

- (2013): “Informe de fiscalización de la gestión económicofinanciera y de la aplicación de la Ley 39/2006, de 14 de diciembre, de Promoción de la Autonomía Personal y Atención a la Dependencia", Madrid. 